\title{
Professional Capacity Building of Multicultural Teaching Assistants in Hong Kong Kindergartens with Ethnic Minority Children
}

\author{
Shek Kam Tse \\ Faculty of Education, The University of Hong Kong, Hong Kong SAR, China \\ Emily Y. W. Pang \\ Faculty of Education, The University of Hong Kong, Hong Kong SAR, China \\ Heiken To \\ Faculty of Education, The University of Hong Kong, Hong Kong SAR, China \\ Pik Fong Tsui \\ Faculty of Education, The University of Hong Kong, Hong Kong SAR, China \\ Lu Sai Lam \\ Faculty of Education, The University of Hong Kong, Hong Kong SAR, China
}

\begin{abstract}
A professional teaching development programme was established to equip multicultural teaching assistants (MTA) with skills and knowledge to teach non-Chinese speaking (NCS) preschoolers in Hong Kong. To evaluate if MTAs are perceived to be able to perform their intended roles (support Chinese and overall learning, provide pastoral support, bridge the communication between NCS parents and kindergartens, and promote social integration), questionnaires were collected from 18 principals and 74 teachers. To assess if the programme can equip MTAs with necessary skills for the planned roles, questionnaires were collected from 39 MTAs, and a focus group interview with 8 MTAs was also conducted. Results showed that principals and teachers were satisfied with MTAs' performances in supporting NCS students' learning. Moreover, the majority of MTAs agreed that the training programme helped them to perform their intended roles in preschools. Most modules taught in the training programme, apart from one exception, were well received by MTAs. The focus group interview revealed that MTAs were satisfied with the programme, though they preferred more training on Chinese writing skills and knowledge in dealing behavioral issues of children. The study shows the possibility of integrating MTAs into multicultural classrooms in Hong Kong to facilitate NCS children's learning.
\end{abstract}

Index Terms-multicultural teaching assistants, second language learning, learning Chinese as a second language

\section{INTRODUCTION}

Traditionally, teaching assistants (TAs) were introduced into educational settings to perform administrative, clerical and routine tasks, with the aim of reducing the workload of teachers (Butt \& Lance, 2009; Groom, 2006; Kerry, 2005; Moran \& Abbott, 2002). However, research has demonstrated an evolution of roles played by TAs in recent years: increasingly they have been taking on paraprofessional work and teaching duties (Butt \& Lowe, 2012; Butt \& Lance, 2009). In a systematic analysis conducted by Sharma and Salend (2016), TAs are shown to perform "pedagogical, assessment, socialization and behavioral roles", as well as "facilitating information sharing among educators and with families, preparing and adapting materials" and fostering "student learning, teaching and inclusion" (p. 121-123). In a similar study, Kerry (2005) conceptualized 11 roles of teaching assistants based on past literature. These include caring for the welfare of students; managing behavior of students both individually and in groups; supporting curriculum planning in tasks, such as lesson-planning and preparation of teaching materials; and specialist roles, such as being interpreters to facilitate the teaching and learning of students speaking in another language. With respect to supporting teaching and learning of students, Radford et al. (2015) suggested that TAs play three scaffolding roles for preschoolers, namely (i) a support role that maintains learner engagement, on-task behavior and motivation; (ii) a repair function that focuses on learning and fostered independence when children were in difficulty; and (iii) a heuristic role that encourages students to use their own learning strategies.

\section{LITERATURE REVIEW}




\section{A. Factors Contributing to the Effectiveness of Teaching Assistants}

When utilized effectively, TAs have a positive impact on student learning, as well as job satisfaction, stress levels and workloads of teachers (Sharma \& Salend, 2016). With the roles of TAs evolving, together with the increasing number of duties taken up by TAs, role confusion is cited by a few studies as a barrier towards effective utilization of TAs (Butt \& Lowe, 2012; Butt \& Lance, 2009). In addition, the increasingly specialized role demands of TAs mean that they may not be adequately equipped with the required knowledge and skills (Radford et al., 2015), with Butt and Lance (2009) noting that more than half of the teachers in their study perceived that TAs needed more training.

Unsurprisingly, the clear definition of roles is listed as a factor contributing to the effectiveness of TAs (Sharma \& Salend, 2016; Moran \& Abbott, 2002), as well as professional training and development (Butt \& Lance, 2009; Bourke \& Carrington, 2007), in the form of targeted skills-based training (Butt \& Lowe, 2012) and professional supervision and feedback (Sharma \& Salend, 2016). Other successful factors include the personal qualities of TAs, their willingness to develop new skills, flexibility, and effective cooperation and support in planning between teachers and TAs. These studies, however, also caution against the risk of students becoming overly dependent on TAs, therefore minimizing the challenges in students' learning, as well as reducing opportunities for students to interact with their classmates (Sharma \& Salend, 2016; Moran \& Abbott, 2002).

\section{B. Teaching Assistants in Inclusive, Multicultural Settings}

Both mainstream and inclusive classrooms have seen an increased use of teaching assistants, with those in inclusive settings requiring more specialized knowledge and skills (Takala, 2007). Groom and Rose (2005) also state that there has been a considerable increase in TAs in the UK appointed to support pupils with special education needs, including those with social, emotional and behavioral difficulties. The role of TAs is perceived as crucial to the effective inclusion of pupils with difficulties in mainstream classrooms.

In Hong Kong, in order to promote the integration of ethnic minority (EM) students into Hong Kong's education system and society, government initiatives have been put in place to encourage them to study in mainstream schools. In an exploratory study by Gao and Shum (2010), mainstream schools sometimes provide additional support, including the provision of bilingual teaching assistants to address the specific needs of those students who face the challenge of learning Chinese as an additional language within the context of central curriculum. The findings indicate that these assistants not only took on the role of helping the EM students in Chinese language acquisition, but also acted as mediators between mainstream school culture and their own cultures. It suggests the importance of the specific roles of bilingual teaching assistants in promoting inclusive education for EM students.

\section{Challenges Faced by Non-Chinese-speaking Students in Learning Chinese in Hong Kong}

Despite the introduction of bilingual teaching assistants in Hong Kong, as with previous studies, training of these teaching assistants was not standardized and did not require formal qualifications (Butt \& Lowe, 2012). Studies highlight a number of challenges that still remain for non-Chinese-speaking (NCS) students in learning Chinese in Hong Kong (Tsung \& Gao, 2012). To list a few prominent ones, these include inadequacy of trained educators in teaching NCS students, cultural and language differences of NCS students and Chinese-speaking (CS) students, and lack of parental support.

Regarding the inadequacy of trained educators, the abolishment of the designated school system has led to more NCS children being admitted into local mainstream kindergartens. This means that educators in the local mainstream system, including teachers and TAs, have encountered difficulties in teaching NCS students. Without extra professional training, most kindergarten teachers would not be able to implement effective instruction in the same classroom that benefits both the local CS students and NCS students.

Cultural differences exist between NCS and CS students. Some EM families have a strong attachment to their own culture. Also, the isolation of these ethnic minorities from the mainstream Chinese culture has limited NCS children's opportunities for developing their Chinese language ability. For instance, NCS children may find it very difficult to catch the content and language used in a lesson - e.g. talking about Chinese festivals and calendars. This undermines children's motivation to learn Chinese, hindering their Chinese language development.

Language differences between NCS and CS students also mean that learning Chinese can be more challenging for NCS students. Chinese uses a logographic writing system without the grapheme-phoneme correspondence, unlike alphabetical systems used in languages of NCS students. Also, unlike English words having a correspondence of sound to their spelling, Chinese characters have no such association.

Parents of NCS students, whose first languages are neither English nor Chinese, often experience difficulties in following their school's instructions and academic requirements. They may feel that local teachers have neglected the specific needs and the cultural and linguistic background of their children. As a consequence of the language barrier, NCS students may not receive the support they could be getting from their parents.

\section{The Need for Structured Professional Capacity Building of Multicultural Teaching Assistants}

Given the above challenges faced by NCS students in learning Chinese in Hong Kong, and the demonstrated potential of teaching assistants in addressing these challenges, there is a need for structured professional capacity building of multicultural teaching assistants (MTAs). Similar to existing TAs, they are required to take on the roles of 
supporting teaching and learning, together with behavioral management, but have an additional role of being specialists (Kerry, 2005) in the areas of bridging the language barrier between schools and NCS students' parents, and facilitating inclusion of NCS students in local schools. The additional cultural role requires MTAs to be familiar with culturally responsive teaching practices, defined as the use of cultural characteristics, experiences and perspective of ethnically diverse students to facilitate effective teaching (Gay, 2002), which serves to increase learning motivation and ease, bridging cultures, and minimizing alienation in the classroom (Chou, Su \& Wang, 2018; Richards, Brown \& Forde, 2007; Gay, 2002).

With the above requirements in mind, MTAs should be trained with a structured programme to perform the various required roles, utilizing relevant knowledge and skills to a standard. Professional development of TAs is considered important (Butt \& Lowe, 2012; Cobb, 2007), and training before commencing work, and career pathways, such as university courses, is recommended. "C-for-Chinese@JC" Project is an EM support programme initiated by The Hong Kong Jockey Club Charities Trust, in which the MTA post is a novel initiative launched to help NCS students during class. To train MTAs, a one-year, theory-practice integrated programme was established in 2016, equipping MTAs with knowledge and relevant skills in the areas of Chinese language, pedagogy, early childhood development, culturally responsive teaching, and promoting social inclusion. As part of their training, MTAs are required to participate in a 6week practicum in local kindergartens with NCS students. Four intended roles are expected to be performed by MTAs after their training:

1. Support learning of Chinese as a second language

2. Foster overall learning and provide pastoral support

3. Take part in engaging parents in kindergartens, facilitating communication between teachers and parents

4. Promote social inclusion of culturally diverse groups and promote racial harmony

\section{THE CURRENT STUDY}

The current study adopts a mixed-methods design, incorporating both quantitative and qualitative data, to address the following questions:

1. Do principals and teachers perceive that MTAs can fulfil their planned roles?

2. What are the expectations of principals and teachers about the MTA post, and/or their training?

3. Do MTAs perceive that the training programme provided equips them to perform their planned roles?

4. What are the expectations of MTAs on their post, and/or their training?

The following is divided into two sections, with the first section concerning the perspective of principals and teachers, addressing study questions 1 and 2, while the second concerns the perspective of MTAs, addressing questions 3 and 4. Uncovering the perceptions of principals, teachers and MTAs will help to paint a picture of how the MTA post can potentially be integrated into kindergartens in the future, such that MTAs can perform their planned roles, and that the expectations of the MTA post from principals, teachers as users, and the MTAs as service providers, can be aligned in a realistic and achievable manner. This provides directions for improvements in the future professional development of the MTAs.

\section{METHODOLOGY (I)}

This section focuses on the perspective of principals and teachers.

\section{A. Participants}

In total, 18 principals and 74 teachers from 20 kindergartens were included in this study; all of them had worked with MTAs in the 2017-18 school year.

\section{B. Instruments and Procedures}

A semi-structured questionnaire, consisting of seven questions on a four-item Likert scale $(4=$ very satisfied, $3=$ satisfied, 2 = unsatisfied, 1 = very unsatisfied), was used to assess whether principals and teachers perceived MTAs to fulfil their planned roles. These questions are grouped according to the four planned roles listed above. To uncover expectations specific to principals and teachers on the MTA post, open-ended questions were included at the end of the questionnaire. Questionnaires were distributed to principals and teachers at the end of the 2017-18 school year. Consent was obtained from them beforehand.

\section{Data Analysis}

Considering that principals and teachers may differ in their perceptions and expectations of MTAs, questionnaire results were analyzed separately. A mean score was calculated for each of the four planned roles. The score was then compared to a reference of 2.5, which is the hypothetical score for an average performance from MTAs. This is done as the study is novel, without previous data for reference. A control group of MTAs was also not practically feasible in schools. Four one-sample t-tests are conducted, with a Bonferroni correction applied to reduce type I error rate (i.e. the criterion value set at 0.0125 ).

The percentage distribution of ratings by principals and teachers were also presented to further uncover any potential 
aspects of the roles that MTAs did well in.

Expectations of principals and teachers were extracted by analyzing the qualitative answers from the open-ended question and identifying common recurring themes mentioned by at least 3 principals or teachers.

\section{RESULtS (I)}

\section{A. Principals' Perception Ratings on MTAs' Performances in the Four Planned Roles}

Cases with missing data were removed, leaving 17 responses from principals. Principals' perceptions on MTAs performance in all the four intended roles were statistically higher than the hypothetical average of 2.5: (i) supporting learning of Chinese as a second language $(\mathrm{M}=3.24, \mathrm{SD}=0.44, t(16)=6.934, p<0.001)$, (ii) fostering overall learning and providing pastoral support $(\mathrm{M}=3.10, \mathrm{SD}=0.35, t(16)=7.067, p<0.001)$, (iii) taking part in engaging parents in kindergartens, facilitating communication between teachers and parents $(\mathrm{M}=3.35, \mathrm{SD}=0.70, t(16)=5.010, p<0.001)$, and (iv) promoting social inclusion of culturally diverse groups, and promoting racial harmony $(\mathrm{M}=3.00, \mathrm{SD}=0.53$, $t(16)=7.034, p=0.001)$. In other words, statistically, principals perceived MTAs to be able to fulfil their four planned roles, with all four performing at level higher than a hypothetically average performance.

Table 1 shows the percentage distribution of principals' ratings on MTA's performance. Across the four intended roles, over $80 \%$ of principals were satisfied with MTA's performance. All the principals agreed that MTAs were able to support the learning Chinese of NCS students.

TABLE 1

Percentage Distribution Of Principals' Perception Ratings On MTAS' Performances In The Four Planned Roles

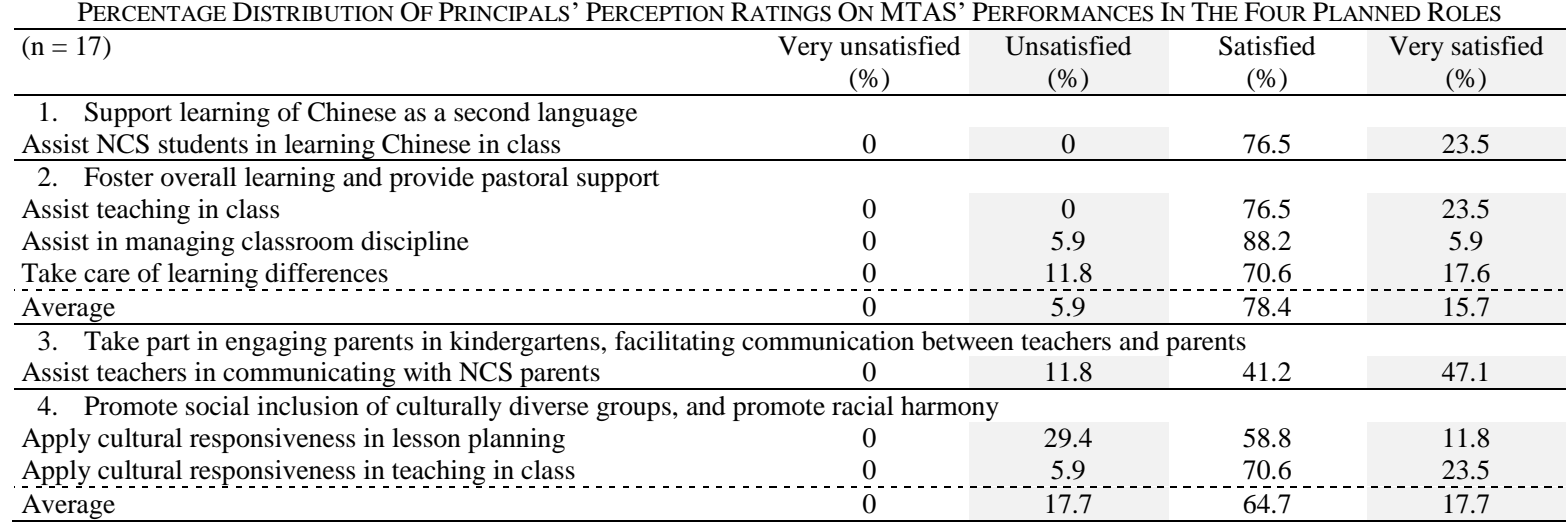

All principals (100\%) perceived that MTAs performed particularly well in the aspects of assisting NCS students in learning Chinese in class, and assisting teaching in class; and the majority of principals (88\%) agreed that MTAs performed best in the aspect of assisting teachers in communicating with NCS parents. Although most respondents $(82 \%)$ were satisfied with MTAs' performance in promoting social inclusion of culturally diverse groups, they thought it would be better if MTAs could better apply cultural responsiveness in their lesson planning.

\section{B. Other Comments from Principals on the MTA Post}

Analysis of answers from the open-ended question revealed that principals expected MTAs to be more proactive in assisting teachers in teaching and in lesson planning, with comments such as "MTAs appear to be passive" and "hoped to see MTAs leading more activities" noted. Moreover, principals would like MTAs to be well-equipped with knowledge, skills and attitudes in early childhood education. Three principals expressed that MTAs should not have their practicum too early, and instead needed "better preparatory work before their practicum at school". Another added that MTAs should be familiar with the curriculum content.

\section{Teachers' Perception Ratings on MTAs' Performances in the Four Planned Roles}

Cases with missing data were removed, leaving 59 responses from teachers. Teachers' perception on MTAs performance in all the four intended roles were statistically higher than the hypothetical average of 2.5: (i) supporting learning of Chinese as a second language $(\mathrm{M}=3.17, \mathrm{SD}=0.56, t(16)=9.154, p<0.001)$, (ii) fostering overall learning and providing pastoral support $(\mathrm{M}=3.12, \mathrm{SD}=0.55, t(16)=8.722, p<0.001)$, (iii) taking part in engaging parents in kindergartens, facilitating communication between teachers and parents $(\mathrm{M}=3.24, \mathrm{SD}=0.65, t(16)=8.682, p<0.001)$ and (iv) promoting social inclusion of culturally diverse groups, and promoting racial harmony $(\mathrm{M}=3.02, \mathrm{SD}=0.56$, $t(16)=7.034, p<0.001)$. In other words, statistically, teachers perceived MTAs to be able to fulfil their four planned roles, with all four performing at a level higher than a hypothetically average performance.

Table 2 presents the percentage distribution of teachers' ratings on MTA's performance. Similar to principals' rating, the majority of teachers (over 85\%) were satisfied with MTA's performance across the four intended roles. 
TABLE 2

Percentage Distribution Of Teachers' Perception Ratings On MTAS' Performances In The Four Planned Roles

\begin{tabular}{|c|c|c|c|c|}
\hline$(\mathrm{n}=59)$ & $\begin{array}{c}\text { Very unsatisfied } \\
(\%)\end{array}$ & $\begin{array}{c}\text { Unsatisfied } \\
(\%)\end{array}$ & $\begin{array}{c}\text { Satisfied } \\
(\%)\end{array}$ & $\begin{array}{c}\text { Very satisfied } \\
(\%)\end{array}$ \\
\hline \multicolumn{5}{|l|}{ 1. Support learning of Chinese as a second language } \\
\hline Assist NCS students in learning Chinese in class & 1.7 & 3.4 & 71.2 & 23.7 \\
\hline \multicolumn{5}{|l|}{ 2. Foster overall learning and provide pastoral support } \\
\hline Assist teaching in class & 0 & 8.5 & 62.7 & 28.8 \\
\hline Assist in managing classroom discipline & 0 & 13.6 & 64.4 & 22.0 \\
\hline Take care of learning differences & 3.4 & 10.2 & 61.0 & 25.4 \\
\hline Average & 1.1 & 10.8 & 62.7 & 25.4 \\
\hline \multicolumn{5}{|c|}{ 3. Take part in engaging parents in kindergartens, facilitating communication between teachers and parents } \\
\hline Assist teachers in communicating with NCS parents & 0 & 11.9 & 52.5 & 35.6 \\
\hline \multicolumn{5}{|c|}{ 4. Promote social inclusion of culturally diverse groups, and promote racial harmony } \\
\hline Apply cultural responsiveness in lesson planning & 5.1 & 16.9 & 61.0 & 16.9 \\
\hline Apply cultural responsiveness in teaching in class & 0 & 6.8 & 72.9 & 20.3 \\
\hline Average & 2.6 & 11.9 & 67.0 & 18.6 \\
\hline
\end{tabular}

Most teachers agreed that MTAs performed particularly well in the aspects of assisting NCS students in learning Chinese in class (95\%), and applying cultural responsiveness in their teaching in class (93\%). They were also very satisfied with MTAs in assisting teachers in communicating with NCS parents. However, some teachers perceived MTAs as not fully functioning in the role of promoting social inclusion of culturally diverse groups, they hoped MTAs could better apply cultural responsiveness in their lesson planning.

\section{Other Comments from Teachers on the MTA Post}

MTAs should have a Proactive Attitude. Six teachers expressed their wish for MTAs to be "more involved and proactive", with two stating that apart from assisting in teaching in class, perhaps MTAs could also "increase the number of times" that they "lead activities themselves".

MTAs should be Well-equipped with Knowledge, Skills and Attitudes in Early Childhood Education. Six teachers hoped that MTAs would be better equipped in terms of early childhood education knowledge, child-care skills, course content knowledge, and practical aspects of working in a kindergarten environment. For example, one teacher mentioned that their MTA "did not teach children to pick up toys on the floor", with another commenting that MTAs needed to "improve their qualities and sense of responsibility... otherwise it will be a burden to teachers".

MTAs should use Chinese More Frequently when Communicating with NCS Students. Three teachers wished that MTAs would communicate with NCS students in Chinese more frequently, with two explaining that "speaking in their native languages too often will lead to NCS students being dependent on MTAs", instead of learning to speak Chinese.

Clear understanding on roles and performance standards of the MTA post. Four teachers wanted a better understanding of the roles and performance standards to be expected from MTAs. One teacher in particular realized that "although there are guidelines, seminars, workshops or professional teacher development courses to support teachers, MTAs' role is different in nature compared to students from other early childhood education programmes", and therefore required clarification of the roles of MTAs. Another teacher mentioned that the programme trainers could "tell the school in advance on expectations towards MTAs (e.g. in teaching plans, teaching)".

\section{Methodology (II)}

This section focuses on the perspective of MTAs.

\section{A. Participants}

In total, 39 MTAs were involved in the study. These included 24 MTAs from the 2017-18 school year, who were invited to fill in a questionnaire. An additional 8 MTAs were invited to participate in a group interview.

\section{B. Instruments and Procedures}

A semi-structured questionnaire, consisting of statements with a five-item Likert scale (4= very high, $3=$ high, $2=$ low, $1=$ very low, n/a), was used to measure MTAs' self-perception on whether they can apply the relevant knowledge and skills learnt after studying in each specific module under the MTA training programme. The statements on each module were grouped according to the four planned roles of MTAs. Taken together, it is used to assess whether MTAs perceive that the training programme provided equips them in performing their planned roles. The MTA self-evaluation questionnaires were distributed to MTAs around the end of the 2017-18 school year in April 2018. Consent was obtained prior to collection of data.

A semi-structured group interview was conducted to complement the questionnaire in providing qualitative information on MTAs' self-perception on whether they fulfilled the planned roles and also on their expectations of the MTA post. The group interview was conducted in April 2020 online using the application Zoom. Consent was obtained prior to collection of data.

\section{Data Analysis}


Similar to Section I, a mean score was calculated for each of the four intended roles. They were then compared to a reference score of 2.5, which is the hypothetical score of self-perception towards an average training programme. Four one-sample t-tests were conducted, with a Bonferroni correction applied to reduce type I error rate, and the criterion value set at 0.0125 . Percentage distributions of the five items (strongly agree, agree, disagree, strongly disagree, n/a) for each question were also calculated to provide further insight into modules that were considered by MTAs to be particularly useful for them in carrying out their intended roles.

For the group interview, the content was transcribed to solicit MTAs' self-evaluation on the four intended roles. Furthermore, MTAs' expectations on their post and/or their training were extracted based on common recurring themes mentioned by at least 3 MTAs.

\section{RESULTS (II)}

\section{A. MTAs' Ratings on Performance on Planned Roles after the Training Programme}

Cases with missing data and with the "n/a" option selected were removed from the analysis, leaving 20 responses from MTAs. MTAs' perception of their ability to perform the role of supporting learning of Chinese as a second language $(\mathrm{M}=3.39, \mathrm{SD}=0.36)$ was statistically higher than the hypothetical average of $2.5, t(19)=10.946, p<0.001$. Their perception of their own performance on the role of fostering overall learning and providing pastoral support (M= 3.47, $\mathrm{SD}=0.38$ ), was also statistically higher than the hypothetical average of $2.5, t(19)=11.431, p<0.001$. Their perception of their own performance on the role of taking part in engaging parents in kindergartens, facilitating communication between teachers and parents $(\mathrm{M}=3.52, \mathrm{SD}=0.46)$, was also statistically higher than the hypothetical average of $2.5, t(19)=9.781, p<0.001$. Lastly, their perception of their own performance on the role of promoting social inclusion of culturally diverse groups, and promoting racial harmony $(\mathrm{M}=3.28, \mathrm{SD}=0.44)$, was also statistically higher than the hypothetical average of $2.5, t(19)=8.026, p<0.001$. In other words, statistically, MTAs perceived that the training programme was able to equip them in performing their four intended roles, at a level that is higher than the hypothetical average.

TABLE 3

Percentage Distribution Of MTAS’ Self-Perception Ratings After Participating In Modules Of The Training Programme, Under THE FOUR PLANNED ROLES

\begin{tabular}{|c|c|c|c|c|c|}
\hline Modules taught & N/A & Very low & Low & High & Very high \\
\hline \multicolumn{6}{|c|}{ 1. Supporting learning of Chinese as a second language } \\
\hline Chinese for early childhood education 1 & 0 & 0 & 0 & 57.3 & 42.7 \\
\hline Chinese for early childhood education 2 & 0 & 0 & 0 & 65.3 & 34.7 \\
\hline Supporting language development of NCS children & 3.1 & 0 & 0 & 61.5 & 35.4 \\
\hline
\end{tabular}

2. Foster overall learning and provide pastoral support

Understanding child development from an ecological perspective

Embracing play-based learning and teaching

0

$0 \quad 0$

40.6

$\begin{array}{lllll}0.6 & 0 & 0 & 55.4 & 44.0\end{array}$

English communication skills in Early Childhood Education

0

Applying technology into learning and teaching resources

1.1

$0 \quad 0$

54.2

45.8

$\begin{array}{llll}0 & 0 & 54.2 & 44.8\end{array}$

3. Take part in engaging parents in kindergartens, facilitating communication between teachers and parents

\begin{tabular}{l}
$\begin{array}{l}\text { Supporting social and emotional development of NCS children in } \\
\text { home and schools }\end{array}$ \\
\hline
\end{tabular}

4. Promote social inclusion of culturally diverse groups, and promote racial harmony

Building culturally responsive classrooms in the local context

04.2

Promoting equality and social inclusion in home-school- 0

community collaboration

\begin{tabular}{|c|c|c|}
\hline 4.2 & 7.3 & 64.6 \\
\hline 0 & 0 & 50 \\
\hline
\end{tabular}

Percentage distributions on ratings showed that almost all MTAs agreed that the training programme provided helped them in performing their intended roles. For the role of supporting learning of Chinese as a second language, all three modules listed received high or very high ratings, meaning that MTAs perceived that they were able to apply the relevant knowledge and skills taught in this area. The same could be said of the four modules under the role of fostering overall learning and providing overall support, as well as the module under the role of engaging parents in kindergartens 
and facilitating communication between teachers and principals. Under the role of promoting social inclusion of culturally diverse groups and racial harmony, the same could also be said for the module "Promoting equality and social inclusion in home-school-community collaboration". For the module "Building culturally responsive classrooms in the local context", however, only $89 \%$ instead of $100 \%$ MTAs gave high or very high ratings. This might suggest that MTAs were expecting more in the course in equipping them with relevant knowledge and skills for building culturally responsive classrooms in the local context.

\section{B. MTAs' Self-evaluation on Performance on Planned Roles through Focus Group Interview}

Support Learning of Chinese as a Second Language. Four MTAs did not report difficulty in performing the role of supporting Chinese learning in NCS students. They made use of their native language to facilitate better understanding of NCS students in learning Chinese, and were able to translate for NCS students and communicate the students' difficulties in learning Chinese to the teachers. To illustrate, one MTA mentioned:

If NCS students don't know how to do their homework, we can use our own language to teach them and let them understand how to do it. The effect seems to be good, they will tell me about their difficulties then I will translate for them to the teachers... I did not experience any problems, as the Chinese used for young children is easy, so I can listen to it and understand.

Foster Overall Learning and Provide Overall pastoral support. Four MTAs perceived themselves to be able to foster overall learning and provide overall pastoral support, especially in the area of managing classroom discipline. They found this role particularly helpful when teachers are busy or may not have the capacity to look after all the children all at once. One MTA even mentioned that she helps observe the needs of students, which the teachers may miss out during class:

In the classroom there are always two teachers, one is the substitute class teacher, and the third one will be the MTA, but sometimes the teachers are very busy handling many things, especially when it's classwork time checking their homework and being in one of the groups. It's not a must that they can look after 32 children at once even if there are two teachers there. So I think we as MTAs play a crucial role, we are there to observe every little thing that the class teacher and the substitute class teacher can miss out on, so we are there to play that role.

When MTAs are not sure how they can assist teachers, they also demonstrated proactiveness in inquiring the needs of teachers:

Most of the time we follow the teachers' directions but sometimes we take the initiative and ask what we can help with.

Take Part in Engaging Parents in Kindergartens, Facilitating Communication between Teachers and Parents. MTAs did not experience issues for the role of engaging parents in kindergartens and facilitating communication between teachers and parents, and did not give many comments. One MTA mentioned that they mainly communicate with teachers using Chinese, using English when necessary. Communication with parents generally involved explanation of school notices and important issues and was usually done in their native languages:

For example in my practicum school, even though we have a permanent NCS student teacher, if she is busy sometimes the teachers ask us to help translate to the parents on some notices or anything important. For the teachers we usually use Cantonese... if we don't know how to say something we will just use English. For the parents we try using English, but first we use our own language.

Promote Social Inclusion of Culturally Diverse Groups and Promote Racial Harmony. Similar to the above point, for the role of promoting social inclusion of culturally diverse groups and promoting racial harmony, not much feedback was given as MTAs did not experience many issues. MTAs showed awareness towards the importance of providing culturally-responsive teaching:

I think it's really important for the class teacher, if there are one to two of them (EM students), at least know what background they are from, because when they are introducing Chinese New Year for example, they (EM students) will have no clue why everything is red. The teachers have to give them more understanding.

MTAs perceived themselves to be able to promote social inclusion of culturally diverse groups, and to promote racial harmony. One illustrated this using differences in religion as an example, reminding teachers of Christian practices that Muslims cannot do, so that teachers will also become more aware of activities to avoid when teaching NCS students with a Muslim background:

If there's something that the teacher doesn't know about us, then we can tell them, for example, like we are Muslim and there's something regarding the Christian religion they're asking us to do, then we can explain to them 'oh we cannot do this because that is not allowed in our religion', so they can also try to avoid other Muslim students doing it, and they can have some knowledge about the religion difference.

\section{Expectations of MTAs on Their Post and/or Their Training}

The MTA Post as a Step Towards Becoming a Kindergarten Teacher. MTAs saw their post as a step towards becoming a kindergarten teacher, with four MTAs stating that they would like to become, or were considering 
becoming a kindergarten teacher sometime in the future, and that the MTA post would provide them with relevant knowledge, skills and practical experience as a stepping stone.

More Realistic and Considered Demands from Teachers and Schools. The second expectation concerned more realistic and considered demands placed on their post from teachers and schools. Two MTAs in particular mentioned that teachers who worked with them expected them to know how to make teaching materials and know all teaching strategies from the beginning of their practicum, only to find out that the materials did not meet the teachers' expectations during class:

Some of the teachers expect us to know most of the things, like how to make teaching materials and how we have the strategies, we have the strategies, but that time we're new to the kindergarten and we went there to learn things. Some of the teachers think that we know the things and they will give us the teaching materials and sometimes they will just teach us once only how to make the teaching materials. When we do not get it and do something wrong, and some of the teachers are busy, you know, and they need the teaching material right away, it feels like sometimes they're annoyed.

This can be understood as the need for a greater understanding of MTA's abilities, and more guidance and communication on expectations from teachers to MTAs. Two other MTAs mentioned their schedules were really packed from the beginning of the practicum, with many subjects to teach in class, and lots of teaching materials to prepare and display boards to decorate after class, which took time to get used to:

The first day was very tiring... I thought they were just going to teach ABCs or something very simple for the first day, but turns out there was a lot to do, they have to make a lot of teaching materials and work on many things. The full day schedule was also very busy, running from this place to that. The subjects are so packed, like Putonghua, Chinese and English.

This reflects the need for more progressive increases in workload for MTAs in their practicum, which would allow for MTAs to slowly adapt to working in the kindergarten environment.

More Support in Chinese Writing Skills in Training, Especially in Lesson Planning. Apart from expectations for their own post, MTAs' comments also revealed one main expectation for their training. Four MTAs mentioned that they would like more support in writing up lesson plans in Chinese, as currently many rely on online translation tools to translate their lesson plans from English to Chinese. Three MTAs found that practicum teachers of their training program, along with teachers of the kindergartens, could be a helpful resource:

In my practicum school, the teacher can actually be quite helpful, the day before I have to do the activities she would help me check it again and help me correct the part... make adjustments or even add in one or two sentences... written she might not understand clearly... after explaining verbally she gets a clear image on how to correct the lesson plan.

They (the practicum teacher) teach us to write the small details you need in a lesson plan, what is the structure of it and how you can write it... I just asked the kindergarten teacher and the practicum teacher for help.

When questioned further, it was found that the current training programme is mainly conducted in English and there is not much emphasis on lesson plan writing in the course content. This suggests that more training in the area of Chinese lesson plan writing is needed.

More Knowledge in Dealing with Behavioral Issues and Special Education Needs in Training. A second minor expectation on the training programme, although only mentioned by one MTA, is also worth pointing out as it concerned the need for more knowledge in dealing with behavioral issues and special education needs in preschoolers. The MTA mentioned that if other MTAs also looked to become a kindergarten teacher in the future, it would be helpful for them to be equipped with knowledge in these areas, as it would also benefit them in their practicum:

I would also like to have a part where the university is teaching us how to find ways to help children having behavioral issues because sometimes children will throw tantrums, or sometimes children are very hyperactive, so you don't know how to deal with them... We should have a syllabus teaching on Special Education Needs... maybe not covering the whole thing, but part of it. In my kindergarten there are a number of students with special educational needs. A majority of them are hyperactive or dyslexic so it's hard for them to learn. As an MTA let's say after this course I go to a school where a majority of them have special education needs. I know how to teach a regular student but for them you have different ways, different skills to help them learn.

\section{DISCUSSION}

Results from the t-tests conducted on the principal, teacher and MTA questionnaires, together with comments from the MTA semi-structured group interview, suggest that MTAs were able to perform the four intended roles at a level higher than a hypothetically average performance after going through the training programme. Distributions in ratings show that both principals and teachers thought MTAs performed well in all the four intended roles: supporting learning of Chinese as a second language, fostering overall learning and providing pastoral support, and taking part in engaging parents in kindergartens, facilitating communication between teachers and parents, promoting social inclusion of culturally diverse groups and racial harmony also received good ratings; but slight improvements could be made in the 
specific area of applying cultural responsiveness in lesson planning. A similar picture is obtained from the MTA questionnaires on their training programme, with modules under the first three roles all receiving positive ratings, with the module "building culturally responsive classrooms in the local context" under the fourth role being the only module with lower ratings.

Butt and Lowe (2012) noted that TAs are increasingly taking on paraprofessional work without professional training to equip them with relevant knowledge and skills, which led to a majority of teachers perceiving that TAs needed more training. The present study demonstrates that it is possible, with the inclusion of a dedicated, structured and professional training programme, for MTAs not only to fulfil roles in supporting teaching and learning, but also to take on specialist roles (Kerry, 2005), such as facilitating communication between students, teachers and parents. In particular, MTAs performed well in the novel specialist role of facilitating social inclusion using culturally responsive teaching practices.

These four intended roles are created specifically to target the more prominent challenges NCS students face in learning Chinese in Hong Kong: inadequacy of trained educators in teaching NCS students, cultural and language differences of NCS students and Chinese-speaking (CS) students, and lack of parental support (Tsung \& Gao, 2012). In light of the above results, the use of MTAs to support NCS students in the school environment can be considered a viable option to address these challenges. It addresses the issue of inadequate trained educators by providing an additional post at schools, without placing too much demand on teachers, who likely already have hefty workloads and may not have the capacity to receive professional training in teaching NCS students. Instead, MTAs play their part in reducing the workload of teachers (Sharma \& Salend, 2016) by supporting them in teaching, not only by preparing teaching materials, but also in translating for them and the NCS students to facilitate better learning.

Crucially, in regards to cultural and language differences between NCS and CS students, MTAs are able to inform teachers about these differences both in lesson planning and in classes, for teachers to then adapt their teaching content, materials and approach in providing a more culturally-relevant and appropriate learning experience for NCS students. For example, when introducing Chinese New Year as a topic, teachers could go into more detail and explanation on the related customs and traditions to compensate for the lack of life experiences of NCS students in this area, and perhaps compare and contrast them to the Islamic New Year celebrations to make the topic more relatable. In supporting actual classroom teaching, MTAs are helpful in translating instructions or new Chinese words for NCS students for them to have better understanding, potentially facilitating quicker learning. Conversely, MTAs also help translate difficulties encountered by NCS students back to the teachers for a better understanding of students' needs.

Parents of NCS students are not able to provide as much support as they can often due to language barriers between them and their schools. MTAs play a mediating role in linking up the two, by providing translations to foster clear communication. For example, they assist in translating notices on school events, or they can help explain the importance of their children in learning Chinese. When incidents occur at school that need parents' attention, such as the students being ill, MTAs can also help explain the situation to parents. Also, MTAs can potentially help link parents to learning or supportive resources in the local community. This increase in communication serves to make parents more aware of their children's learning situation at school, and consequently, they may be more willing to be involved in supporting their learning.

Moving on to the expectations of principals and teachers on MTAs, both were similar in that they hoped for MTAs to possess the qualities of being more proactive and be well-equipped with early childhood-relevant knowledge and skills. As Moran and Abbott (2002) suggested, the success of TAs depends on personal qualities in addition to knowledge and skills, which is an area for further improvements in future MTA training programmes.

Teachers had two additional expectations, the first of which is having a clearer understanding of MTAs' duties and performance standards. This expectation, in particular, aligned with MTAs' expectations of more realistic and considered demands from teachers and schools. This suggests that perhaps teachers were not informed well enough on the abilities and duties of MTAs, and inadvertently placed expectations, in areas such as teaching material preparation and assigned workload at the beginning of the practicum, that were out of reach for MTAs. This led to MTAs perceiving the need for more realistic and considered demands. In other words, consistent with previous literature (Sharma \& Salend, 2016; Butt \& Lowe, 2012), there seems to be some role confusion outside the four intended roles. The MTA training programme perhaps offered greater visibility of training opportunities, which, as Butt and Lance (2009) mentioned, altered the perceptions of teachers and raised their expectations. As Moran and Abbott (2002) suggest, for better utilization of MTAs, better teamwork is needed to clarify additional roles and responsibilities of MTAs outside that of the four intended roles, that while meeting the needs of teachers, should be within their competencies.

Teachers also expected MTAs to use Chinese more frequently in communication with NCS students. This concern is not unfounded as Sharma and Salend (2016) also cautioned that TA effectiveness may be compromised by students' over-dependence on them, lowering the challenges of learning tasks and potentially isolating these students from the rest of the class, giving them fewer opportunities to interact with their peers. This could be clarified during the MTA training programme, and also between teachers and MTAs should this issue arise.

From the interview, it is clear that most MTAs saw their post as a stepping stone towards becoming a kindergarten teacher. They also expressed the expectations of better training in Chinese writing skills in lesson planning, and knowledge in dealing with behavioral issues and special education needs, both of which are important if they are to 
become teachers. Continuous professional development is considered important for TAs (Butt \& Lowe, 2012; Bourke \& Carrington, 2007; Cobb, 2007). With the expectations of MTAs in mind, the construction of a career ladder could be considered, helping MTAs transition into teachers. Given their existing training in teaching NCS students, they would also be better equipped and ready to teach classes with NCS students.

The current study demonstrates the feasibility of using novel MTAs in addressing the challenges faced by NCS students in learning Chinese in Hong Kong. MTAs not only perform existing roles such as supporting NCS students' learning of Chinese and providing pastoral support at schools, but more importantly, also acting as mediators and interpreters between schools and parents, and serving to promote social inclusion of students from diverse cultural backgrounds at school. This is one of the first studies of TAs taking on these cultural roles in the local school setting, made possible through a dedicated, structured and professional training programme. Further improvements can be made in the areas of developing personal qualities of MTAs and clarifying additional roles and responsibilities between teachers and MTAs. Career progression for MTAs to become teachers is also worth exploring.

\section{DisCLOSURE STATEMENT}

No potential conflict of interest was reported by the authors.

\section{ACKNOWLEDGMENTS}

This work and the “C-for Chinese @ JC" project were supported by The Hong Kong Jockey Club Charities Trust.

\section{REFERENCES}

[1] Bourke, P., \& Carrington, S. (2007). Inclusive education reform: Implications for teacher aides. Australasian Journal of Special Education, 31(1), 15-24.

[2] Butt, G., \& Lance, A. (2009). 'I am not the teacher!': Some effects of remodelling the roles of teaching assistants in English primary schools. Education 3-13, 37(3), 219-231.

[3] Butt, R., \& Lowe, K. (2012). Teaching assistants and class teachers: Differing perceptions, role confusion and the benefits of skills-based training. International Journal of Inclusive Education, 16(2), 207-219.

[4] Chou, P.-I., Su, M.-H., \& Wang, Y.-T. (2018). Transforming teacher preparation for culturally responsive teaching in Taiwan. Teaching and Teacher Education, 75, 116-127.

[5] Cobb, C. (2007). Training paraprofessionals to effectively work with all students. The Reading Teacher, 60(7), 686-689.

[6] Gao, F., \& Shum, M. S. K. (2010). Investigating the role of bilingual teaching assistants in Hong Kong: An exploratory study. Educational Research (Windsor), 52(4), 445-456.

[7] Gay, G. (2002). Preparing for Culturally Responsive Teaching. Journal of Teacher Education, 53(2), 106-116.

[8] Groom, B. (2006). Building relationships for learning: The developing role of the teaching assistant. Support for Learning, 21(4), 199-203.

[9] Groom, B., \& Rose, R. (2005). Supporting the inclusion of pupils with social, emotional and behavioural difficulties in the primary school: The role of teaching assistants. Journal of Research in Special Educational Needs, 5(1), 20-30.

[10] Kerry, T. (2005). Towards a typology for conceptualizing the roles of teaching assistants. Educational Review, 57(3), $373-384$.

[11] Moran, A., \& Abbott, L. (2002). Developing inclusive schools: The pivotal role of teaching assistants in promoting inclusion in special and mainstream schools in Northern Ireland. European Journal of Special Needs Education, 17(2), 161-173.

[12] Radford, J., Bosanquet, P., Webster, R., \& Blatchford, P. (2015). Scaffolding learning for independence: Clarifying teacher and teaching assistant roles for children with special educational needs. Learning and Instruction, 36, 1-10.

[13] Richards, H. V., Brown, A. F., \& Forde, T. B. (2007). Addressing diversity in schools: Culturally responsive pedagogy. TEACHING Exceptional Children, 39(3), 64-68.

[14] Sharma, U., \& Salend, S. J. (2016). Teaching assistants in inclusive classrooms: A systematic analysis of the international research. Australian Journal of Teacher Education, 41(8), 118-134.

[15] Takala, M. (2007). The work of classroom assistants in special and mainstream education in Finland. British Journal of Special Education, 34(1), 50-57.

[16] Tsung, L., \& Gao, F. (2012). What accounts for the underachievement of South Asians in Hong Kong? The voices of Pakistani and Nepalese parents. Educational Research, 54(1), 51-63.

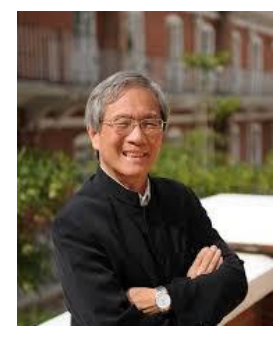

Shek Kam TSE is a professor at the Centre for Advancement of Chinese Language Education and Research (CACLER), Faculty of Education, The University of Hong Kong. His research interests include: (1) teaching Chinese as a second language; (2) the influence of interventions on early literacy development; and (3) effective Chinese language pedagogy for different stages of education. 
Emily Y. W. Pang is research manager at the Centre for Advancement of Chinese Language Education and Research (CACLER), Faculty of Education, The University of Hong Kong. She has been involved in educational research in the areas of teacher professional development and growth; pedagogies and the contemporary curriculum; and parent/family/community involvement. Her research interests have revolved around the school as a professional learning community, with special attention to teachers' enactment in different aspects of change in schools and policies and the student's perspective on learning.

Heiken To is a research associate at the Centre for Advancement of Chinese Language Education and Research (CACLER), Faculty of Education, The University of Hong Kong.

Pik Fong Tsui' is a senior research assistant at the Centre for Advancement of Chinese Language Education and Research (CACLER), Faculty of Education, The University of Hong Kong.

Lu Sai Lam is a deputy project manager at the Centre for Advancement of Chinese Language Education and Research (CACLER), Faculty of Education, The University of Hong Kong. 